\title{
Value-Chain Analysis Of Prohibition In The United States, 1920-1933: A Historical Case Study In Marketing
}

Ed Petkus, Jr., Ramapo College of New Jersey, USA

\begin{abstract}
The federal ban on the manufacture, distribution, and sale of alcoholic beverages in the United States from 1920-1933 provides a unique and fascinating context for understanding fundamental marketing processes. The most direct pedagogical outcome of this case is the application of value-chain marketing dynamics within the context of Prohibition. Students will also be made aware of the importance and relevance of understanding marketing history, and the role of marketing in history. This case study is primarily intended for use in intermediate (e.g., Retailing/Distribution) or advanced (e.g., Marketing Management) marketing courses, but is adaptable for introductory courses (e.g., Principles of Marketing).
\end{abstract}

Keywords: marketing history; value-chain dynamics

's Friday night in New York City. A group of college seniors goes out for a night on the town. They're
dressed fashionably and they are looking forward to an evening of music, dancing, food and, yes, maybe
a couple of drinks. There's just one small catch: it's 1927, and it's illegal to sell alcoholic beverages in the United States.

\section{NATIONAL PROHIBITION IN THE UNITED STATES}

On January 16, 1920, the Eighteenth Amendment to the Constitution, enforced by the federal legislation known as the Volstead Act, took effect in the United States, prohibiting the manufacture, sale, and distribution of alcoholic beverages. (At the national level, consumption of alcohol was not prohibited, though many states instituted laws, for varying amounts of time, that made consumption illegal as well.) Set within the context of reform that was characteristic of the Progressive era, Prohibition legislation was the result of decades of lobbying by groups such as the Anti-Saloon League, the Women's Christian Temperance Union, the Salvation Army, and scores of individuals and smaller organizations.

The overt justification for Prohibition was generally positioned as a call for an enhancement of the moral and physical health of the nation. In addition to the political and social lobbying organizations, other industries either overtly or implicitly supported, or at least welcomed, Prohibition legislation for competitive advantage reasons. These industries included soft drinks, coffee, tea, candy, chewing gum, and ice cream, all of whom anticipated increased sales. The motion picture and theatre industries also stood to benefit, offering "dry" alternatives on which consumers could spend their money and evening leisure hours.

But despite all of this support, the group of collegiate merrymakers will not necessarily be thwarted in their objective to have a few drinks. It is widely accepted that Prohibition, once implemented, was generally a failurethat is, that the manufacture, distribution, and sale (and, correspondingly, the consumption) of alcoholic beverages continued (after a brief initial decline) during the years 1920 to 1933. Of course, quantitative analyses that demonstrate this are rare, but surrogate measures of consumption showed that alcohol consumption fell to thirty percent of the pre-Prohibition level during the first few years, but then increased to 60-70 percent of pre-Prohibition 
level, where it remained through 1933. After the repeal of Prohibition, alcohol consumption levels increased back to pre-Prohibition levels within a decade.

Ultimately, the impossibility of enforcement and the rise of organized crime that was attributed to the illegal alcohol trade resulted in the repeal of Prohibition, via the Twenty-First Amendment, in 1933. While complex political dynamics certainly contributed to the repeal of Prohibition, perhaps a more interesting question is: how, and why, did so much alcoholic beverage consumption continue while the law was still in effect?

\section{U.S. PROHIBITION-ERA ALCOHOLIC BEVERAGE PRODUCTION, DISTRIBUTION, \& MARKETING}

\section{Production}

During the Prohibition-era, alcoholic beverage production took three distinct forms: foreign manufacturing, domestic manufacturing, and at-home manufacturing. Foreign manufacturing of alcoholic beverages sold and consumed in the U.S. during Prohibition occurred primarily in Canada, Mexico, and the Caribbean, while a smaller but still significant amount also came from Europe. These imports included beer, wine, and spirits. (For obvious reasons, exact numbers and breakdowns are impossible to obtain.) Domestic production occurred on a wide range of levels, from single-gallon "bathtub" sole proprietorships to large-scale undercover manufacturers capable of producing hundreds of barrels per month. Re-distillation was the process by which denatured alcohol (which, under the Volstead Act, was legal to manufacture for industrial purposes) could be turned into consumable ethyl alcohol-based beverages by producers with the proper distillation equipment.

Technology development was an on-going process as alcoholic beverage producers sought to develop methods of production that satisfied consumer demand while remaining clandestine and profitable. Such technological innovations also involved "product development" methodologies that ranged from relatively sophisticated biochemistry to simple but creative "blending" to produce palatable alcoholic beverages (Lerner 2007; Willing 1926).

Though small by absolute standards, home manufacturing was responsible for significant amounts of beer and wine, as well as lesser amounts of liquor (while home-brewing and distilling equipment was not illegal to sell or purchase, the distillation apparatus necessary to produce spirits was much more complex to operate than fermentation apparatus). Home manufacturing often involved the use of "essences," which were mixed with sugar and ethyl alcohol to create such beverages as vermouth, benedictine, crème de menthe, and sloe gin. These essences (as well as "wine bricks" such as Vine-Glo and non-alcoholic malt extracts that were legally manufactured and sold) often included clever instructions that were "disguised" as warnings, informing the buyer not to add alcohol, because that would be illegal. Women became increasingly likely to serve as at-home manufacturers of alcoholic beverages - their recipes could be found in cookbooks, etiquette manuals, and even fictional novels.

\section{Distribution}

During Prohibition, the primary distribution method for consumable alcoholic beverages was generally known as "bootlegging" (the term probably originated in describing illegal distributors who would smuggle liquor in bottles tucked into their boots). The overall process of bootlegging can be broken down into four specific functions: smuggling, alteration, warehousing, and wholesaling.

Smuggling processes involved all movement of alcoholic beverages into and within the U.S., either overland or via coastal access. In general, overland smuggling was cheaper but riskier than coastal access smuggling, which, due to the vast amount of coastline, was difficult to police. Trucks and cars were the primary long-range mode of overland transportation. Coastal smuggling generally operated as follows: large ships transported the cargo to a designated point outside U.S. territorial waters, where it was shifted to smaller boats and delivered to the coast, usually in areas that were difficult for law enforcement personnel to access, such as small inlets or marshy areas (Andersson 2002). Rail was also used fairly extensively, though it was less flexible and required more complicated bribery networks (Merz 1930). 
While beer and wine were typically sold unadulterated after import, most of the liquor was either watered down or otherwise altered in an effort to gleaner higher profits (Lerner 2007). The alteration process would be carried out at various points in the logistical process, depending on the transportation and storage dynamics. Warehousing also took various forms, from well-hidden and well-guarded large scale operations to smaller, temporary storage facilities. Because of their static nature, warehouses were primary targets for law enforcement agencies. The last stage was the wholesaling function, in which alcoholic beverages were sold to nightclubs, cabarets, speakeasies, and other "retail" outlets (Walker 1933; Willing 1926).

\section{Marketing, Sales, \& Service}

The retail stage of the Prohibition-era alcoholic beverage marketing consisted of three main outlets: nightclubs and cabarets, speakeasies, and supplementals. As retail outlets, nightclubs/cabarets, speakeasies, and supplementals sold alcoholic beverages in two ways: on-premises, which naturally carried with it a service function, and off-premises, where the product was taken away for at-home consumption. In all on-premises retail contexts, consumer ingenuity resulted in myriad ways to conceal and consume alcohol, such as hollow canes and "hot water" bottles (Perrett 1982). Supplementals included other legal retailers that illegally sold alcohol, "walking saloons" (individuals who walked the streets and sold shots of liquor from concealed flasks to passersby), boats anchored outside the legal coastal limits, and the legal forms of alcohol sale (medicinal use and sacramental wine). Each of these retail forms will be examined in detail in the following sections.

\section{Nightclubs/Cabarets}

Before Prohibition, the main on-premises retail outlets for alcoholic beverages were hotels and restaurants that catered to a generally upscale clientele, and taverns and saloons that catered to a generally working-class clientele. As the Prohibition era unfolded, the upscale hotels and restaurants found themselves in a bind: due to competitive pressure, they needed to serve liquor in order to stay in business; but because they were high-profile outlets, they were easy targets for law enforcement. This situation resulted in an evolution to the nightclub/cabaret, which sold both alcoholic beverages and entertainment to an upscale clientele (Lerner 2007). While the entertainment aspects of the nightclub experience served as a thin cover for the marketing of alcoholic beverages, they represented a form of "value-added" that resulted in extra revenues and provided a legitimate "benefit" that nightclub owners could overtly offer in advertising and other marketing communication (Aaron and Musto 1981).

While it might seem that under conditions of restricted marketing, alcoholic beverages, where available, would "sell themselves," nightclubs and cabarets often found creative ways to "up-sell" their clientele. These included cover charge-based pricing systems, promotional mechanisms, and the employment of "hostesses"women who would flirt with male patrons for the sole purpose of eliciting increased drink purchases (Lerner 2007). In addition, some nightclubs audaciously advertised the availability of alcohol, in some cases even publishing price lists. These establishments likely counted on bribery schemes and complex methods of concealment to protect them from law enforcement (Aaron and Musto 1981).

\section{Speakeasies}

In contrast to the nightclub/cabaret, the "speakeasy," (also called, less commonly, the "blind pig"), sold alcoholic beverages but offered no formal entertainment. The speakeasy evolved from the pre-Prohibition taverns and saloons, terms that referred to any bar or tavern that served alcoholic beverages. Like the nightclubs and cabarets, the speakeasies often used membership cards and secret passwords in an attempt to ensure that their clientele remained free of undercover law-enforcement agents. Again, for obvious reasons, word-of-mouth and social networking were the primary means of communicating the location and availability of the establishments (Lerner 2007).

In general, the speakeasies catered to a lower socio-economic market segment than the nightclubs and cabarets. Indeed, the local speakeasy often served an important social bonding and networking function in many urban working-class neighborhoods (Kingsdale 1973). While saloons prior to Prohibition had mostly banned the 
patronage of women, the speakeasies welcomed them (Perrett 1982). Not surprisingly, as the presence of women in the speakeasies became more common, prostitution often emerged as a complementary service (Worthington 1929).

Perhaps because of the lack of a legitimate "cover" that the nightclubs enjoyed, speakeasies became more notorious for their methods of alcoholic beverage concealment. Examples included trap doors, hidden rooms, falsebottomed bars, and pre-poured drinks that could be quickly spilled into a trough upon the arrival of authorities (Aaron and Musto 1981).

\section{Supplementals}

In addition to nightclub/cabarets and speakeasies, a variety of legitimate retailers sold alcoholic beverages to customers. Cigar stores, barbers, tailors, and grocers were just some of the common places where people could obtain alcohol illegally. As with the other retail outlets, communication would be almost entirely through word-ofmouth, and de facto "memberships" were common. Elaborate methods, similar to those used by nightclubs and speakeasies, were used to conceal their efforts from law enforcement (Lerner 2007).

As described earlier, "walking saloons" were a unique form of retail marketing—and arguably a precursor to modern day drug-dealers, pimps, and ticket scalpers. Medical prescriptions could be used to legally acquire alcohol, making physicians and pharmacists an important aspect of the retail function - and one that required a bit of social networking. In addition, up to ten gallons of sacramental wine were allowed to certain families for religious purposes; however, it is certainly possible that the consumption of sacramental wine also occurred outside of the ceremonial context (Lerner 2007).

A final interesting form of alcohol retailing was the use of off-shore boats as floating saloons (known as "Rum Rows" by the U.S. Coast Guard), which from the start of Prohibition took advantage of the three-mile offshore limit of federal law enforcement authority. This retail form obviously catered to a relatively upscale clientele who could afford a sufficient boat (or passage on one) to gain access to these unique retail outlets. However, in 1925, the limit was extended to twelve miles, which severely diminished the off-shore alcoholic beverage market (Aaron and Musto 1981).

Ultimately, all of the retail outlets discussed above were faced with a common set of marketing challenges. First, they were faced with increased costs of supply (including the costs of evading detection and potential punishment for being caught). In addition, Prohibition resulted in generally increased costs to consumers. These costs included overall higher prices (estimated to be roughly thrice those of pre-Prohibition prices), as well as increased search costs, costs of consuming unsafe products, costs of being cheated by adulterated products, and the potential psychological costs of participating in a consumption context that is deemed by many to be immoral and that was, in essence, illegal (Miron and Zwiebel 1991). Given this restrictive context, the degree to which alcoholic beverage consumption was sustained during Prohibition is a testament to the power of the marketing system that evolved.

\section{Discussion/Application Questions:}

Q1: Apply a value-chain analysis to the manufacturing, distribution, and consumption of alcoholic beverages during Prohibition. Draw a value-chain model that illustrates your analysis.

Q2: Develop a marketing mix analysis that accounts for all aspects of the manufacturing, distribution, and consumption of alcoholic beverages during Prohibition.

Q3: Imagine that Prohibition were implemented today. What external environmental factors would facilitate marketing processes differently than 1920-1933? What factors would be the same?

Q4: Imagine that you were a nightclub owner during Prohibition. What unique "marketing" efforts might you undertake? How might these differ if you were a speakeasy owner? 
Q5: In your opinion, did alcoholic beverage "marketing" really occur during Prohibition, or was it a manifestation of consumption without marketing? Please explain.

Q6: Make a list of other historical contexts in which marketing played a significant role. For each, discuss the marketing concepts that are illustrated and the potential relevance to present-day marketing.

\section{Teaching Notes:}

- This case is adaptable for use in a range of marketing courses and course-levels. Q1 assumes that valuechain analysis has been covered in the curriculum (e.g., Retailing \& Distribution or Marketing Management course). Q2 can be used alternatively in an introductory course (e.g., Principles of Marketing). Discussion Questions 2-5 are adaptable to any marketing course.

- $\quad$ Figure One provides instructors an example of one way to construct a value-chain model to describe the marketing dynamics of alcohol during Prohibition. Porter's (1985) value-chain analysis model consists of two main categories of functional activities. Primary activities represent core value-delivery functions, including inbound logistics, operations, outbound logistics, marketing and sales, and service. Support activities are value-adding functions that act in concert with primary activities to complete the value-chain. Support activities include general administration, human resource management, technology development, and procurement functions.

- It is important to emphasize the "big picture" in this case. This case is less about the details of applying marketing techniques than it is about understanding marketing processes holistically - how all the pieces fit together. Instructors can emphasize the power of consumer demand: while the exact reasons for the failure of Prohibition are complex, a significant part of the failure must be attributed to the powerful market forces that drive mutually-beneficial exchange processes in marketing.

- Q5 raises an almost-philosophical question: is it possible to call a process a "marketing" process if the standard elements of environmental analysis, strategy development, planning and execution of the marketing mix, and evaluation and control did not explicitly occur? If not, then modern illegal consumption contexts (e.g., narcotics, prostitution, gambling, etc.) would also need to be considered outside of the marketing realm. Indeed, much current research in the fields of health care and alcohol, tobacco, and drug policy examines the implications of prohibition of those products. On the other hand, if a broader perspective is adopted, the marketing dynamics that occurred during Prohibition can perhaps offer insights into these modern contexts. This would clearly have implications for social policy, law enforcement, and even health care. At the very least, this question forces students to ponder the fundamental nature of marketing processes.

- This case also illustrates the importance and relevance of understanding marketing history, and the role of marketing in history. Q6 directly elicits student response to extend the understanding of marketing in the historical context.

- This case is deliberately designed to be short enough to be implemented in a single class period. In addition, it demonstrates that important pedagogical outcomes from case studies are not limited to quantitative analyses.

Ed Petkus, Jr. (Ph.D., University of Tennessee) is an Associate Professor of Marketing in the Anisfield School of Business at Ramapo College of New Jersey. As a marketing educator, Petkus is interested in the relationship between marketing and the liberal arts. As a marketingologist, Petkus is fascinated by the interface of marketing processes and socio-cultural phenomena, both in the present and throughout history. Petkus would like to thank his students for their support in the refining of this case study.

\section{REFERENCES}

1. Aaron, P., and Musto, D. 1981. Temperance and prohibition in America: An historical overview. In Alcohol and Public Policy: Beyond the Shadow of Prohibition, edited by Moore, M. H., and Gerstein, D. R., 127-81, Washington, DC: National Academy Press. 
2. Andersson, H. 2002. Illegal entrepreneurs: a comparative study of the liquor trade in Stockholm and New Orleans 1920-1940. Journal of Scandinavian Studies in Criminology and Crime Prevention; 3 (2) 2002 , pp.114-134

3. Blocker, J. S., Jr. 2006. Did prohibition really work? Alcohol prohibition as a public health innovation. American Journal of Public Health 96(2): 233-44

4. Calkins, R. 1919. Substitutes for the Saloon. Boston: Houghton-Mifflin.

5. Kerr, K. A. 1985. Organized for Prohibition: A New History of the Anti-Saloon League. New Haven: Yale University Press.

6. Kingsdale, J. M. 1973. The 'poor man's club': Social functions of the urban working-class saloon, American Quarterly 25: 472-89.

7. Gaski, J. F. 1999. Does marketing ethics really have anything to say? - A critical inventory of the literature. Journal of Business Ethics 18(3) 315-35.

8. Lerner, M. 2007. Dry Manhattan. Cambridge: Harvard University Press.

9. Levine, H. G. and C. Reinarman 1991. From prohibition to regulation: lessons from alcohol policy for drug policy. Milbank Quarterly 69(3): 461-94.

10. Merz, C. 1930. The crusade starts. Outlook and Independent, reprinted in The Dry Crusade, edited by Mowry, G. E. 1963. p. 89-93, The Twenties: Fords, Flappers, and Fanatics, New Jersey: Prentice-Hall.

11. Miron, J. A. 1998. An economic analysis of alcohol prohibition. Journal of Drug Issues 28(3): 741-62.

12. Miron, J. A. and J. Zwiebel 1991. Alcohol consumption during prohibition. The American Economic Review 81(2): 242-7.

13. Murdock, C. G. 1998. Domesticating Drink: Women, Men, and Alcohol in America, 1870-1940. Baltimore: Johns Hopkins University Press.

14. Perrett, G. 1982. America in the Twenties: A History. New York: Simon and Schuster.

15. Porter, M. E. 1985. Competitive Advantage: Creating and Sustaining Superior Performance. New York: The Free Press.

16. Roiblatt, R. E., and M. C. Dinis 2004. The lost link: Social work in early twentieth-century alcohol policy. Social Science Review 78: 652-74.

17. Walker, S. 1933. The Night Club Era. New York: Stokes.

18. Webb, H. 1999. Temperance movements and prohibition. International Social Science Review 74 (1and2): $61-9$.

19. Willing, J. K. 1926. Profession of bootlegging. Annals of the American Academy of Political and Social Science, reprinted in The Dry Crusade, edited by Mowry, G. E. (1963) p. 93-103, The Twenties: Fords, Flappers, and Fanatics, New Jersey: Prentice-Hall.

20. Worthington, G. E. 1929. The night clubs of New York. Survey. reprinted in The Dry Crusade, edited by Mowry, G. E. (1963) The Twenties: Fords, Flappers, and Fanatics, p. 413, New Jersey: Prentice-Hall. 
Figure One:

Prohibition-Era

U.S. Alcoholic Beverage Marketing/Value-Chain Dynamics

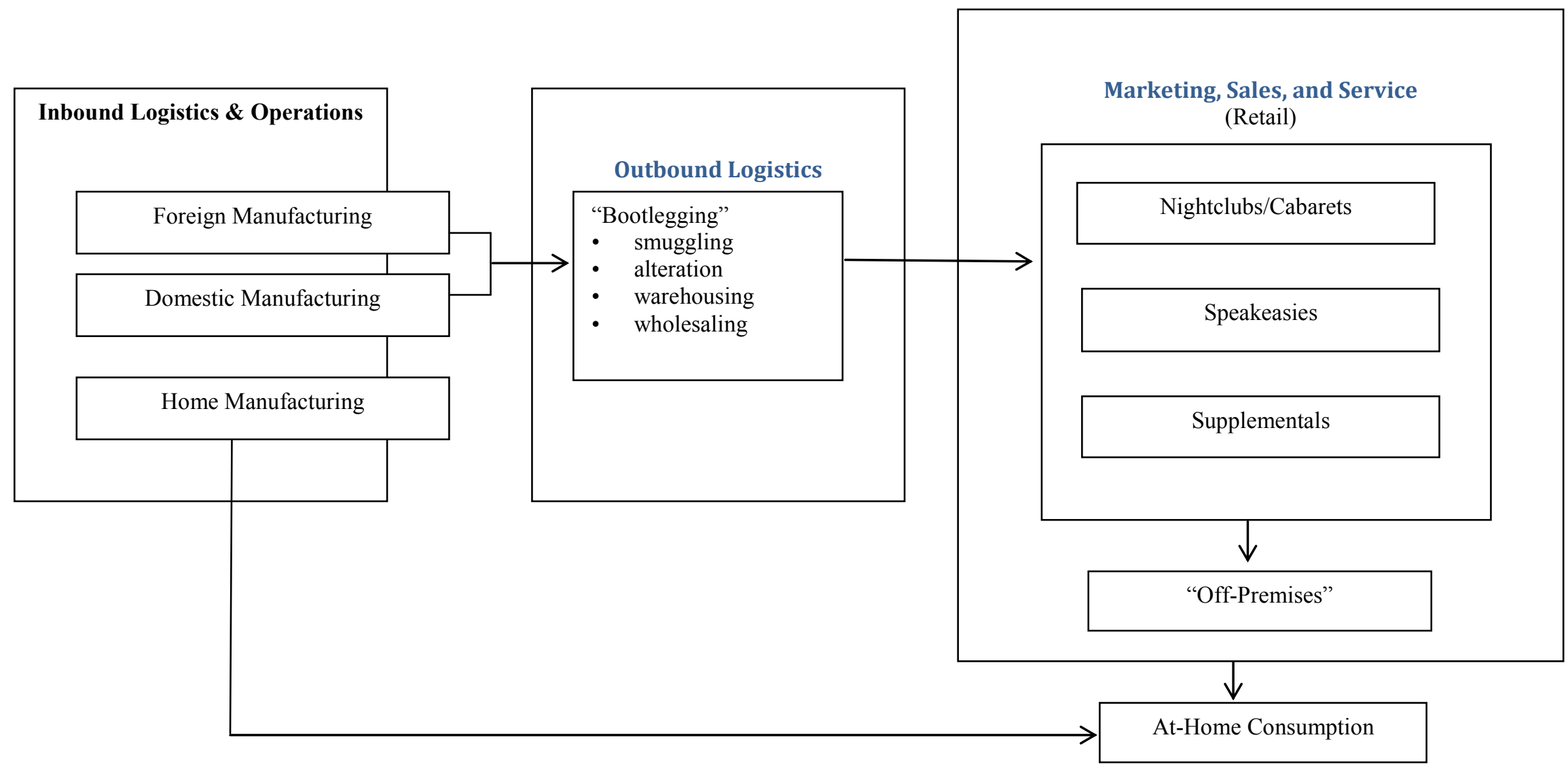




\section{NOTES}

